\title{
Efficiency analysis of information technology and online social networks management: An integrated DEA-model assessment
}

\author{
Margarita Martínez-Núñez , Waldo Saul Pérez-Aguiar \\ Department of Business Organization, Management and Statistics. Technical University of Madrid, Carretera de Valencia, km 7, 28031 Madrid, Spain
}

\begin{abstract}
A B S T R A C T
This paper analyses the relationship between productive efficiency and online-social-networks (OSN) in Spanish telecommunications firms. A data-envelopment-analysis (DEA) is used and several indicators of business "social Media" activities are incorporated. A super-efficiency analysis and bootstrapping techniques are performed to increase the model's robustness and accuracy. Then, a logistic regression model is applied to characterise factors and drivers of good performance in OSN. Results reveal the company's ability to absorb and utilise OSNs as a key factor in improving the productive efficiency. This paper presents a model for assessing the strategic performance of the presence and activity in OSN.
\end{abstract}

\section{Introduction}

Online social networks (OSNs) understood as any application that allows its users themselves to collaborate in its content, has engendered a new philosophy or attitude to user-oriented websites that is increasingly valued by businesses. OSNs are seen as the technology which has grown more in recent years [47]. In less than five years, these sites have evolved from being specialised online activities, becoming a phenomenon involving tens of millions of Internet users [45].

The progressive incorporation of these new interactive technologies can bring various benefits to businesses, such as reducing the costs of customer service, improving market research, involving consumers in the process of designing new products, and increasing brand awareness, among others. These OSNs are not, therefore, merely sales-generating instruments; rather, in sales terms, they complement the online distribution services [13].

In Spain, the use of social networking among consumers is well advanced; but businesses lag behind. The penetration of traditional companies into the world of Web 2.0 has been limited, in most cases to mere presence i.e. simply appearing in the most popular 2.0 sites and services [40]. But not all business sectors have

Corresponding author. Tel.: +34913365230.

E-mail address: margarita.martinez@upm.es (M. Martínez-Núñez). embraced Web 2.0 with the same speed or depth. In fact there are marked differences in the benefits gained through the use of social technologies by companies in one sector compared to those in another [54]. The telecommunications sector has the greatest number of companies with at least one measurable benefit through Web 2.0 technologies, worldwide [54]. The telecommunications sector has been chosen in this study since it is a key sector for Web 2.0 technologies in Spain

In this paper, OSNs have been treated as an interactive technological resource and have been considered as specific services and applications within the Information Technology and Communication (ICT). The following Web 2.0 tools have been evaluated: Twitter, Facebook, YouTube, blogs, and other technologies already built into the firms as business web-sites, and developing platforms like mobile web .mobi. This study focuses on 2.0. technology management, due to the fact that platforms that support OSNs are public and free, any company can get a profile and access identical functions and use them with the intensity they want, unless the company chooses to develop its own technology solution. The activity of an actor in OSN is perfectly visible and repeatable by all others, creating a great diversity of activities in the OSN. This circumstance could predict a set of homogeneous resources which did not influence the firms' efficiency levels.

This paper aims to analyse the productive efficiency of the companies that make up the telecommunications sector in Spain, and whether efficiency is improved by the addition of 2.0 
technology indicators. Besides, this article intends to determine their ability to assimilate these technologies and if 2.0 technologies can be considered as a scarce, valuable and heterogeneous resource. Due to the newness and on-going development of 2.0 technologies, there is a dearth of studies or empirical data providing indicators that might help corporate managers with its evaluation. This article aims to contribute to filling this gap.

This paper begins with a brief background of the application of DEA in the telecommunication sector and to the Information and Communications Technologies. After the integrated DEA-model is presented, Section 4 sets out the material and data collected. The next section shows the results obtained in different models, which are discussed and compared in Section 6 together with some strategic implications. Section 7 describes the limitations of this work and gives some implication for future research. Conclusions are drawn in the final section.

\section{Background}

There is a strong tradition of the application of DEA in this area to assess efficiency and productivity through the use of financial resources, both at the corporate and market level. Internationally, in recent years, studies have emerged which compare efficiency among firms in the telecommunication sector: Debnath et al. [21] in India, Mahdavi et al. [48] in Iran, Hisali et al. [38] in Uganda, Yang et al. [79] in Taiwan. The work of Tsai et al. [75] studied the efficiency of the 39 top global operators.

The application of DEA has evolved over time and is now regarded as an appropriate methodology for relating efficiency outcomes to features of organisational design. The sources of relative inefficiency can be identified by DEA [44].

From this perspective there are various studies that address the behaviour of business units by introducing, in addition to financial resources, other factors available to the companies in carrying out their strategies, such as physical and human resources: Durand et al. [25] in France, Majumdar [50] and Majumdar and Venkataraman [51] in the telecommunications industry in the U.S.A.

The utilisation and impact of technological resources, such as Information and Communication Technology (ICT) in combination with other tangible and human resources, is analysed by quantifying efficiency, in studies such as Fernández-Menéndez et al. [32] of the Spanish manufacturing industry, Sigala [68] of the UK hotel industry, Serrano-Cinca et al. [66] of Internet and ecommerce firms.

Recently, DEA has been incorporated into the resources analysis just like technological resources at market-level. Along these lines, Emrouznejad et al. [28] proposed a method of evaluating the use of ICT in 183 industrialised countries; and Ceccobelli et al. [14] studied the relationship between implementation and use of ICT and increased productivity in 14 OECD countries.

\section{Methodology}

The methodological contribution of this paper is the proposal of a new DEA-based model to analyse the relationship between the productive efficiency and online-social-networks (OSN) in Spanish telecommunications firms. This new model is made up of the following approaches.

(1) Data envelopment analysis (DEA) is used to estimate efficiency.

(2) Super-efficiency DEA sensitivity analysis is implemented to detect outliers and overcome the sensitivity of DEA measurements to the presence of outliers.

(3) Bootstrapping DEA technique is applied to improve the deterministic nature of DEA approach. This procedure allows us to obtain unbiased efficiency estimation.
(4) Logistic regression is employed to explore the factors that promote impact and the drivers of a good performance in the use and management of Web 2.0. technologies and OSNs in efficient firms.

\subsection{Data envelopment analysis (DEA)}

In this study, data envelopment analysis-DEA has been chosen as non-parametric technique to measure the relative efficiency of firms. Techniques developed to measure efficiency require the estimation of a production frontier compared to which a firm's performance may be evaluated. Non-parametric techniques do not specify the functional form of the frontier. Instead these techniques establish a set of segments linking efficient units (firms) which is used to compare the rest of the units [22].

The main reason that motivated the choice of DEA in this study is the fact that the technique does not predefine any functional form for the production function. In addition, in principle it is not financially-oriented, instead the objective is to perform an analysis of the process of transformation of inputs into outputs that generate a measurement or set of measurements, that reflect the efficiency of a firm with regard to this transformation process. DEA has the additional advantage that it can incorporate any number of inputs and outputs into the analysis, and, moreover, these inputs and outputs can be of any nature; the only necessity is the availability of a unit of measurement which allows the assessment of its magnitude [32].

Since its genesis [15] until today, several models of data envelopment analysis have been developed, based on the orientation (input- or output-oriented), the existence of constant or variable returns to scale (and in the latter case, whether they are increasing or decreasing), and whether or not the inputs can be controlled, among others. The first model that has been applied in this study was the one initially proposed by Charnes et al. [15] and known by the authors' initials, CCR. This model involves constant returns to scale and is input-oriented. Following on from Cooper et al. [18], it is based on the traditional definition of efficiency, the ratio of outputs to inputs, and the idea is to find weightings such that through linear programming this ratio can be maximised. Thus, to calculate the efficiency of $n$ units, $n$ linear programming problems must be solved in order to obtain both the values of the weightings $\left(v_{i}\right)$ associated with the inputs $\left(x_{i}\right)$ and the values of the weightings $\left(\mu_{r}\right)$ associated with the outputs $\left(y_{r}\right)$. The inputoriented CCR model, assuming $m$ inputs and $s$ outputs would be formulated in its multiplier form [18], transforming the fractional programming model into a linear programming problem:

$$
\begin{array}{ll}
\max z=\sum_{r=1}^{s} \mu_{r} y_{r o} & \\
\text { subject to } & \\
\sum_{r=1}^{s} \mu_{r} y_{r j}-\sum_{i=1}^{m} v_{r} x_{i j} \leq 0 & i=1,2, \ldots, m ; \\
\sum_{i=1}^{m} v_{r} x_{i o}=1 & r=1,2, \ldots, s ; \\
\mu_{r}, \quad v_{i} \geq \epsilon>0 & j=1,2, \ldots, n .
\end{array}
$$

Similarly, given the absence of information on the shape of the production frontier, we use a model like that shown in (1), but which has the property of allowing variable returns to scale. This model is known, in honour of its authors, as BCC [5]. When inputoriented, the multiplier form of the BCC model becomes 
subject to

$$
\begin{array}{ll}
\sum_{r=1}^{s} \mu_{r} y_{r j}-\sum_{i=1}^{m} V_{i} X_{i j}+\mu_{0} \leq 0 & \\
\sum_{i=1}^{m} V_{i} X_{i o}=1 & i=1,2, \ldots, m \\
\mu_{r}, v_{i} \geq \epsilon>0 & r=1,2, \ldots, s \\
& j=1,2, \ldots, n
\end{array}
$$

where $\mu_{0}$ is the variable that allows us to identify the nature of the returns to scale (increasing, constant or decreasing), following the theorem presented by Banker and Thrall [6]. Note that the model does not require that the variable $\mu_{0}$ take a positive value i.e. it is a free variable.

In this analysis we have chosen the input-oriented DEA model, mainly because the outputs are quite diverse and because a strategic effort is unlikely to succeed long-term if it means excessive cost of production, distribution or organisation [78]. According to these models, a unit would be efficient if it produced the maximum amount in outputs using the smallest possible amount in inputs, and would be assigned an efficiency score of 1 .

\subsection{Super-efficiency DEA sensitivity analysis: Outliers detection}

Due to the sensitivity of DEA measurements to the presence of outliers, some additional procedures are required in order to make DEA efficiency estimates more robust. In this paper, a computational approach for outliers' detection named superefficiency is applied [3]. The essence of this approach is to reduce the impact of the most influential companies on the final efficiency scores, using the concept of leverage. Leverage of a single observed DMU may be understood as a measure of the impact on the efficiency scores of all the other DMUs by the removal of one DMU from the data set [3]. Firstly, the original DEA is applied for each of the DMUs using the original data set, to obtain the set of efficiencies $\left\{\theta_{k} \mid k=1,2, \ldots, K\right\}$. Then, one by one, each DMU is successively removed, and the set of efficiencies $\left\{\theta_{k}^{*} \mid k=1,2, \ldots, K ; k \neq j\right\}$ is recalculated each time, where index represents the removed DMU. The leverage of the th DMU may then be defined as standard deviation:

$l_{j}=\sqrt{\frac{\sum_{k=1, k \neq j}^{K}\left(\theta_{k j}^{*}-\theta_{k}\right)^{2}}{k-1}}$.

This super-efficiency DEA analysis enables an extreme efficient unit to achieve an efficiency score greater than one (so it is called super-efficiency). We have applied a conservative rule of thumb where units with efficiencies (super-efficiencies) of 2 or above are treated as outliers [4]. The outlier DMUs (firms) have been excluded from the sample data used in this work.

This sensitivity analysis using the super efficiency model developed by Andersen and Petersen [3] also contributes to DMUs homogeneity. This analysis looks for "outliers" which are DMUs whose observations prove to be extreme points on the efficient frontier and that could lead to unrealistic efficiency values for some of the other units in the sample

\subsection{Bootstrapping DEA technique}

DEA efficiency is highly sensitive to errors in the data. Given that the DEA method uses a sample for the analysis of efficiency, specific differences in estimations may be due solely to sampling noise rather than true differences in the levels of efficiency of the units. In order to solve this problem in this paper, a bootstrap approach is used. Bootstrapping, introduced by Efron [27], is based on the idea of resampling from an original sample of data to create replicate datasets from which we can make statistical inference. The "smoothed bootstrap" approach of Simar and Wilson [70] is used in this study, and the theoretical underpinnings can be found in the extensive work by Simar and Wilson [70-72].

The key assumption behind this approach is that the known bootstrap distribution will imitate the original unknown distribution if the known data generating process (DGP) is a consistent estimator of the unknown DGP. The common approach is to nonparametrically estimate the original densities of the performance scores using kernel smoothing methods, combined with a reflection method [69]. The bootstrap process will, therefore, generate values that imitate the distributions which would be generated from the unobserved and unknown DGP [71,72]. The bootstrapping process used can be summarised as follows

(1) Calculate the DEA efficiency score $\hat{\theta}_{i} ; i=1,2, \ldots, n$ with the original data by solving model (1).

(2) Use Kernel density estimation and the reflection method to generate a random sample $\left\{\theta_{i}^{*} ; i=1,2, \ldots, n\right\}$ with replacement from the original DEA efficiency score $\hat{\theta}_{i}$.

(3) Generate the $\tilde{\theta}_{i}^{*}$ using $\tilde{\theta}_{i}^{*}=\theta_{i}^{*}+h \epsilon_{i}^{*}, \quad i=1,2, \ldots$, nwhere $\epsilon_{i}^{*}$ is a random draw from a standard normal distribution and $h$ is a control parameter.

(4) Obtain the $\theta_{i}^{* *}$ through

$$
\theta_{i}^{* *}=\bar{\theta}^{*}+\frac{\tilde{\theta}_{i}^{*}-\bar{\theta}^{*}}{\sqrt{1+h^{2} / s^{* 2}}}, \quad i=1,2, \ldots, n
$$

where $\bar{\theta}^{*}$ and $s^{* 2}$ are the empirical mean and variance $n$ of the values $\theta_{i}^{*}$.

(5) Generate resampled pseudo-efficiencies $\gamma_{i}^{*}$ using

$$
\gamma_{i}^{*}= \begin{cases}2-\theta_{i}^{* *}, & \text { if } \theta_{i}^{* *}<1 \\ \theta_{i}^{* *}, & \text { otherwise. }\end{cases}
$$

(6) Obtain a new data sample using $\left(x_{i}^{*}, y_{i}\right)=\left(\frac{\gamma_{i}^{*}}{\hat{\theta}_{i}} x_{i}, y_{i}\right)$

(7) Calculate the DEA efficiency score $\left\{\hat{\theta}_{i}^{*} ; i \stackrel{\left(\hat{\theta}_{i}\right.}{=} 1,2, \ldots, n\right\}$ with data $\left(x_{i}^{*}, y_{i}\right)$,

(8) Repeat steps 2 to $7 B$ times to create a set with $B$ efficiency estimates for each unit $\left\{\hat{\theta}_{i, b}^{*} ; i=1,2, \ldots, n ; b=1,2, \ldots, B\right\}$

The bootstrap estimate of the DEA bias is obtained through

$\operatorname{bias}_{i}=\frac{1}{B} \sum_{b=1}^{B} \hat{\theta}_{i, b}^{*}-\hat{\theta}_{i}, \quad i=1,2, \ldots, n$.

A bias corrected efficiency estimator is then obtained by defining

$\tilde{\theta}_{i}=2 \hat{\theta}_{i}-\frac{1}{B} \sum_{b=1}^{B} \theta_{i, b}^{*}, \quad i=1,2, \ldots, n$.

\subsection{Logistic regression}

Finally, this model intends to characterise the factors that promote impact and the drivers of a good performance in the use and management of Web 2.0. technologies and OSNs in efficient firms. For this, a logistic regression analysis is carried out. This analysis explores the relationship between efficient firms and several business activity variables and web-based technology activity indicators. Following the model proposed by Diaz-Balteiro et al. [22], the aim of this analysis is to model the relationship between a binary response variable (one $=$ efficiency; zero $=$ no efficiency) and each of the selected explanatory variable. A univariate logistic regression uses the binomial distribution to model the variation in a binary response $[1,64]$. 
The probability to be efficient may be expressed by a parameter $p$ in a binomial distribution. If we denote by $Z$ the efficiency response variable and by $x_{i}$ the selected explanatory variable, the relationship between $Z$ and $p$ is the following:

$p=P\left[Z=1 \mid x_{i}\right]$

Thus, for the probability to be efficient, $p$ may be modelled as follows:

$\ln \left(\frac{p}{1-p}\right)=\beta_{0}+\beta_{1} x_{1}$

This model is fit using maximum likelihood. The goodness-of-fit is analysed from the percentage of deviance the model accounts for. This value is similar to the $R$-square statistic. Thus, if the $p$ value is less than 0.05 , there is a statistically significant relationship between efficiency (variable $Z$ ) and $x_{i}$.

Binary logistic regression was selected because the assumptions undergirding logistic regression impose no requirements about the distribution of the predictor variables (e.g., normally distributed, linearly related, equal variances). Logistic regression is a very flexible regression analysis in terms of the type of the explanatory variables, as these can be scaled or categorical. In the DEA literature, given the bounded nature of DEA scores, the logistic regression model is regarded as a suitable methodology for a further DEA analysis $[22,39,41,45,46,61,81]$.

\section{Data}

The population analysed are the companies in the telecommunications sector, according to the Spanish National Classification of Economic Activities (NCEA 61: telecommunications sector). We used two different sources of information. Firstly, the information concerning the use of Web 2.0 technologies is based on metrics of their Web 2.0 activity, obtained directly from the Web 2.0 tools themselves. These measurements were applied to the period MaySeptember 2011. Secondly, complementary information has been compiled from the economic and financial data of these firms (number of employees, equity, debt, revenue and pre-tax profit), from a commercial database [23]. Although there are models to assess variables with negative values in data envelopment analysis (DEA) like the BAM (bounded adjusted measure) proposed by Cooper et al. [17], it has been necessary to normalise negative values due to the characteristics of the DEA model applied in this work.

\subsection{Input-output indicators of OSN-DEA model}

The emergence and popularisation of Web 2.0 and its increasingly widespread use in the business world is a relatively recent phenomenon, so there are still no widely-accepted and implemented standards of measurement for the evaluation of the performance of investment in Web 2.0. In fact, in Spain, over $50 \%$ of companies base their evaluation of the effectiveness of their investment in Web 2.0 technologies on the number of website hits, fans of the company, followers or subscribers [73].

Starting from these criteria, we have chosen indicators that represent the support for and acceptance of a company in social networks through readily-available basic quantitative metrics which allow us to monitor the progress of the company's presence on Web 2.0. The concept of "fans" or "followers" can be related to the concept of "unique visitors" used as an output by SerranoCinca et al. [66]: the larger the number of visitors, the greater the advertising revenue and the greater the potential customers. The same methods can be applied to the increase in numbers of fans or followers on social networks. The other technological variables have inherent features linked with the social media phenomenon, their success is based on the interaction between users and the bidirectional communication.

Web 2.0 technologies are characterised by two types of variables. Firstly, response levels: number of fans, followers, hits, comments and tweets received. These variables have been treated as outputs, since their data are generated by the users and/or potential customers of the company. Secondly, company activity levels: comments, tweets, followings, responses, publications/ posts, applications, events, surveys. These variables measure the company's participation and have been treated as inputs, since it is the company that generates them.

In order to evaluate the results of business management, sales and pre-tax profits have been included as outputs of the model; as inputs, one relates to the firm's labour production factor, number of employees, another to its liabilities structure equity (€) and the third, total assets (€), incorporates both its intangible and tangible assets [68]. In addition, other variables have been considered: timespan of the business regarding the evolution of the Internet with reference to 1995 (emergence of Web 1.0) and to 2005 when O'Reilly [58] spread the term Web 2.0, the fulfilment of international trade activities, the business model either B2C (Business to Consumer) or B2B (Business to Business).

The selected companies are considered Decision-Making Units (DMUs) for the purpose of the application of this study's methodology. Haas and Murphy [37] proposed the following conditions: that the DMUs are engaged in similar processes, using comparable resources to produce comparable outputs. The selected units meet those conditions, since they all belong to the same NCEA group (telecommunications sector). By the same token, the same measures of efficiency apply to all the DMUs, and all those measures operate under the same conditions. Therefore, homogeneity among DMUs is assumed.

In order to ensure the condition of homogeneity of DMUs, a selection process was followed. For the first step, the Spanish National Classification of Economic Activities (NCEA) has been revised to select a homogenous set of firms of the Spanish telecommunications sector. This classification gives the most clear and distinguishing definition of the economic sectors that are part of the Information and Communication Technologies. We have selected those firms that were included in NCEA Code 61: telecommunications sector. The companies of the Spanish telecommunications sector carry out a large number of integrated and specialised activities and services. They all share a common environment where market deregulation and the fast technological revolution are creating a new value chain for the firms of this sector. At this moment the telecommunications sector is one of the most dynamic and productive in Spain. In addition, to maximise consistency in the accounting data, only those companies for which data from both sources were available in 2011 and which have at least one employee have been included in the analysis. Individuals or companies which declare no employees and a turnover of less than $3,000,000 €$ have been excluded, reducing the number of firms analysed to 149. This procedure's first step ensures the "same processes" and "same environment" conditions [37] for DMUs homogeneity.

The second step of this process is carried out when selecting the inputs, the outputs and the variables associated with Web 2.0 technologies. Farzipoor et al. [31] propose that the relative efficiency of somewhat non-homogeneous DMUs can be evaluated reliably by DEA models if there are variables (inputs/outputs) in common for all of them. In this paper, we have selected a set of inputs that all designated companies use and a set of outputs that all designated firms produce. The selected variables associated with Web 2.0 technologies contribute to homogeneity. The selected platforms that support virtual social networks are public: 
Table 1

Distribution among sub-sectors of the selected sample.

\begin{tabular}{lll}
\hline Sub-sector & Firms & $\%$ \\
\hline 61 Telecommunications services & 47 & 31.54 \\
6120 Wireless telecommunications & 45 & 30.20 \\
6190 Other telecommunications activities & 23 & 15.44 \\
6110 Cable telecommunications & 29 & 19.46 \\
6130 Satellite telecommunications & 5 & 3.36 \\
\hline
\end{tabular}

any company can obtain a user login and gain access to the same functionality, without any kind of control or restrictions of use by competitors. Also, a user's activity is completely transparent, and replicable by anyone else. Any company could acquire OSN management abilities in the market at a standard price. This procedure's second step ensures the "same inputs used and same outputs produced" conditions [37] for DMUs homogeneity.

In addition, the super-efficiency DEA sensitivity analysis for outliers' detection [3] model presented in this paper contributes to DMUs homogeneity (see Section 3.2).

The distribution among sub-sectors, following the Spanish National Classification of Economic Activities (NCEA), of the 149 selected firms are shown in Table 1

Table 2 lists all quantitative variables used and its descriptive statistics for the 149 companies of the Spanish telecommunications sector.

One of the main problems associated with the application of this methodology is the correct choice of inputs and outputs. Sexton et al. [67] state that efficiency estimates cannot decrease with the mere introduction of variables, without any selection method. Furthermore, Dyson et al. [26] show that the omission of highly correlated variable may have a significant impact on the efficiency estimates of certain production units. Nataraja and Johnson [57] offer guidelines for effective variable choosing in DEA.

Table 2

Descriptive statistics of the variables used for the OSN-DEA model.

\begin{tabular}{|c|c|c|c|c|}
\hline \multicolumn{5}{|c|}{ Business management } \\
\hline & Average & Total & Std. devn. & Range \\
\hline Number employees & 415.13 & 61439.00 & 2375.90 & $28369[69] .00$ \\
\hline Total assets ${ }^{a}$ & 989.76 & 146484.34 & 7500.78 & 88440.47 \\
\hline Equity $^{\mathrm{a}}$ & 93.38 & 13819.72 & 476.09 & 4563.99 \\
\hline Sales ${ }^{a}$ & 341.36 & 50521.80 & 1611.16 & 12183.61 \\
\hline Profits $^{\mathrm{a}}$ & 72.16 & 10678.97 & 408.78 & 2994.17 \\
\hline \multicolumn{5}{|c|}{ Online social network management ${ }^{\mathrm{b}}$} \\
\hline Twitter & Average & Total & Std. devn. & Range \\
\hline Number of Accounts & 1.23 & 59.00 & 0.47 & 2.00 \\
\hline Tweets & 526.95 & 77988.00 & 1429.29 & 7782.00 \\
\hline Followers & 3020.11 & 446977.00 & 13782.03 & 107899.00 \\
\hline Following & 624.47 & 92422.00 & 2780.99 & 23012.00 \\
\hline Facebook & Average & Total & Std. devn. & Range \\
\hline Number of accounts & 1.27 & 56.00 & 0.65 & 3.00 \\
\hline Fans & 55217.80 & 8172234.00 & 368277.59 & 3890336.00 \\
\hline Post & 15.45 & 2287.00 & 58.39 & 621.00 \\
\hline Comments & 286.28 & 42369.00 & 2298.94 & 27361.00 \\
\hline Others on Facebook & 283.11 & 41900.00 & 2841.67 & 34485.00 \\
\hline Youtube & Average & Total & Std. devn. & Range \\
\hline Number of channels & 1.54 & 57.00 & 0.95 & 4.00 \\
\hline Number of videos & 201.68 & 7.462 .00 & 345.88 & 1740.00 \\
\hline Views & 85072.46 & 3147681.00 & 215910.03 & 1188298.00 \\
\hline Subscribers & 527.41 & 19514.00 & 1440.45 & 7526.00 \\
\hline
\end{tabular}

\footnotetext{
a Millions euros.

b The description of some of these variables is: Tweet: messages received or send by users in their profile. Followers: number of followers of the profile. Following: number of profiles followed by the user. Fans: number of users that follows a profile. Post: events on the user' Facebook wall. Comments: comments of other users to the events of a Facebook profile' Wall. Others on Facebook: number of applications, videos, notes, photos, of the profile.
}

The method ECM (Efficiency Contribution Measure), developed by Pastor et al. [59], has been chosen in this work for variable selection. Nataraja et al. (2011) conclude that ECM performs moderately well under most scenarios. Besides, ECM works well with low correlation among inputs and a large sample size $(n>100)$. ECM can also identify input contribution to output and is slightly affected by choice of the DEA Model technology (CRSConstant Returns to Scale or VRS-Variable Returns to Scale-).

The ECM (Efficiency Contribution Measure), proposed by Pastor et al. [59], is based on analysing the relevance of a variable to be introduced into the model in terms of its contribution to efficiency. For ECM methodology, a candidate variable is considered relevant to the production process if more than $P_{0} \%$ of the production processes have an associated change in efficiency greater than $\rho$ [57], ECM is developed as a hypothesis test with a binomial statistical test.

Therefore, following Pastor et al. [59], we have selected $P_{0}=15 \%$ and $\rho=10 \%$ for the analysis carried out in this work. Also, a significance level $(\alpha)$ of $5 \%$ is set. If the test statistic is less than the null hypothesis, a candidate variable is rejected and is considered to be part of the production process. A forward selection procedure is used and initially input $x_{1}$ and output $y$ are included in the production function, all candidate variables are tested, and the variable with the lowest test statistic below the $\alpha$ value is added to the production model. The ECM is repeated on the new candidate set with one less variable. The process stops when all candidate variables have a test statistic larger than $\alpha$, or no variables remain in the candidate set [57].

Finally, a correlation analysis of the candidate variables was carried out to ensure consistency and reasonability of the selection of inputs and outputs. Peer variables with a correlation coefficient greater than 0.7 are considered highly correlated [52] and have been excluded of the model. Appendix B shows the Pearson's correlation coefficients of the performed analysis.

Particularly, sales and profit have been selected because they present a moderate correlation $(r<0.7)$. From a purely financial and managerial point of view, sales, as an output factor, are a significant indicator of the operational efficiency of a firm. In addition, profits are a key indicator of the managerial efficiency because this term includes all the production activities (costs) of a firm. Sales and profits, both together as output factors of a DEA Model, are very relevant and useful indicators of the efficiency of a firm. Sales are linked with online marketing and online reputation improvement. Profits are related to other concepts or noneconomic benefits in which social networks can introduce modifications and are not directly related to sales, such as human resources management, open or technological innovation or costumer relationship management (CRM).

Table 3

Variables selected for each model.

\begin{tabular}{|c|c|c|c|c|}
\hline & $\begin{array}{l}\text { Model } 1 \\
\text { (Basic) }\end{array}$ & $\begin{array}{l}\text { Model } 2 \\
\text { (Twitter) }\end{array}$ & $\begin{array}{l}\text { Model } 3 \\
\text { (Facebook) }\end{array}$ & $\begin{array}{l}\text { Model } 4 \\
\text { (Twitter + Facebook) }\end{array}$ \\
\hline \multicolumn{5}{|l|}{ Inputs } \\
\hline Employees & 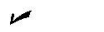 & $\nu$ & $\sim$ & 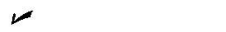 \\
\hline Assets & $\boldsymbol{\nu}$ & $\nu$ & 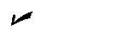 & $r$ \\
\hline Equity & $\nu$ & $\nu$ & $\nu$ & r \\
\hline Tweets & & $\nu$ & & $\nu$ \\
\hline Following_Tweets & & $\nu$ & & $\nu$ \\
\hline Posts & & & $\sim$ & 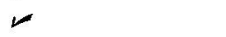 \\
\hline \multicolumn{5}{|l|}{ Outputs } \\
\hline Sales & 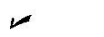 & 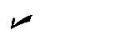 & $\sim$ & 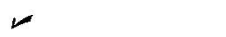 \\
\hline Profits & $\sim$ & $\nu$ & $\sim$ & 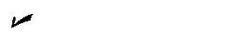 \\
\hline Followers & & 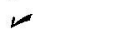 & & 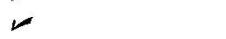 \\
\hline Fans & & & $r$ & $\nu$ \\
\hline Comment received & & & $r$ & $\nu$ \\
\hline
\end{tabular}


Table 4

Selected variables for the logistic regression model.

\begin{tabular}{lrr}
\hline \multicolumn{3}{c}{ Business management } \\
\hline & Firms & $\%$ \\
\hline & Timespan & \\
After 2005 & 8 & 5.37 \\
Between 2005 and 1995 & 85 & 57.05 \\
Before 1995 & 56 & 37.58 \\
Business model & 112 & \\
B2B & 37 & 75.17 \\
B2C & 17 & 24.83 \\
International trade & & 11.41 \\
Online social network management & 48 & 32.21 \\
Has Twitter & 44 & 29.53 \\
Has Facebook & 37 & 24.83 \\
Has Youtube & 31 & 20.81 \\
Has blog & 138 & 92.62 \\
Has website & 44 & 29.53 \\
Has Mobile web platforms mobi & & \\
\hline
\end{tabular}

Moreover, a firm registering higher sales need not register higher profits [80], at least for a certain period of time. Both sales and profits need to be examined in relation to how managers choose to expend resources, so the economics of the company can be better understood

The simultaneous use of sales and profits in efficiency evaluation with data envelopment analysis (DEA) has been described on several occasions in the scientific literature $[7,8,16,22,25,30,63,65]$.

Once ECM is applied and correlation coefficients analysed, the variables selected in each of the four models analysed (see Section 5) are presented in Table 3.

\subsection{Indicators of the logistic regression model}

Table 4 shows the variables of the 149 firms of the Spanish telecommunications sector, selected for the logistic regression model.

\section{Results}

For the sensitivity analysis and the bootstraped-data envelopment analysis (DEA), PIMDEA software [29] was used. STATSGRAPHICS Centurion XV software was used to collect logistic regression model indicators. As a base case for comparison (Model 1: Basic), a business management DEA model has been chosen which includes 3 inputs (number of employees $\left[x_{1}\right]$, equity $\left[x_{2}\right]$ and assets $\left[x_{3}\right]$ ), and two outputs (sales $\left[y_{1}\right]$ and pre-tax profits $\left[y_{2}\right]$ ). This model provides an overall value of low average efficiency, along with a clear means of distinguishing between the units (companies). The results in terms of the efficiency of different companies are shown in Table 5, which gives a descriptive analysis of the efficiency coefficients, prior to applying the sensitivity analysis

As mentioned, this study applies the principle of reduction of inputs, being the most common policy for improvements that companies use. The telecommunications sector has an average efficiency of $33 \%$ or $43.84 \%$ depending on the DEA-model orientation used (CCR and BCC. respectively). This indicates that companies in the sector could achieve the same activity levels in terms of turnover and pre-tax profits, with potential input savings of $67 \%$ based on constant returns, and $56.16 \%$ based on variable returns.

Of the sample of companies analysed, 18 can be seen to be globally efficient, working to optimal scale. On the BCC DEA-model orientation, the number of efficient firms rises to 23, meaning that there are 5 companies that, being technically efficient, could scale their activities in order to be efficient in global terms. Also, the dispersion in rates of efficiency of all models is similar and exceeds $30 \%$ in all cases. The percentage of efficient firms is $12.08 \%$ according to the CCR DEA-model orientation, or $15.44 \%$ according to the BCC DEA-model orientation. This shows that the levels of both global and operational or management inefficiency are very high in the sector as a whole: there is clearly a group of companies that are efficient (in management and in scale) while the rest are inefficient in both areas, as the large deviation indicates. Efficiency scores are relatively low for a market as competitive and increasingly deregulated as the telecommunications market in Spain.

Other DEA models (Model 2, Model 3 and Model 4) have been devised for the calculation of global productive efficiency. These analyse the impact of introducing various different Web 2.0related variables (see Table 3 ). The CCR DEA orientation (constant returns) prevents the convexity restriction that the BCC DEA orientation (variable returns) imposes. Cantos at al [11] consider that the CCR DEA orientation presents efficiency results equal to or less than those with BCC DEA orientation. According to these authors, the choice of constant returns to scale (CCR DEA orientation) is more demanding in terms of efficiency than variable returns (BCC DEA orientation).

In addition, the CCR DEA-model orientation's measurement of efficiency is most often used when incorporating technological variables $[66,68]$. Table 2 shows all variables used and descriptive statistics for the year under review. Therefore, CCR-DEA-orientation is selected for the implementation of our models. After the CCR DEAmodel orientation is chosen, an outlier detection analysis (superefficiency) is implemented to the 4 models (CCR DEA-model oriented), following Andersen and Petersen [3] (see Section 3).

Once the outliers has been detected and excluded from the 4 models, the CCR DEA orientation with the remaining DMUs is applied again to the 4 models. The results for the different models calculated are shown in Table 6. A trend can be seen associating the efficient firms with indicators of their involvement in Web 2.0. The results also show an increase in average efficiency for companies that use both platforms studied. The use of one or the other platform shows no significant difference between them. The heterogeneity of efficiency is maintained where the dispersion is higher than $30 \%$ as measured by the standard deviation.

The potential input savings of incorporating at least one platform is $8.68 \%$ and $4.94 \%$ (average efficiency increase of Model 2 and Model 3 with respect to Model 1, respectively). This means

Table 6

Results of the four models applied (outliers excluded).

Original DEA Efficiency coefficients (model 1)

\begin{tabular}{lccc}
\hline & CCR & BBC & Escale \\
\hline No efficient DMUs & 18 & 23 & 18 \\
\% Efficient DMUs & $12.08 \%$ & $15.44 \%$ & $12.08 \%$ \\
Average efficiency & 33.00 & 43.84 & 33.13 \\
Standard deviation & 32.25 & 34.86 & 32.33 \\
Maximum & 100 & 100 & 100 \\
Minimum & 1.21 & 3.33 & 1.12 \\
\hline
\end{tabular}

\begin{tabular}{lcccc}
\hline & Model 1 & Model 2 & Model 3 & Model 4 \\
\hline No outlier removed & 4 & 7 & 5 & 5 \\
Average efficiency & 32.39 & 41.07 & 37.33 & 56.14 \\
Average efficiency score & 25.20 & 30.75 & 29.43 & 39.70 \\
$\quad$ of inefficient DMUs & & & & \\
Max & 100 & 100 & 100 & 100 \\
Min & 1.50 & 4.24 & 2.42 & 9.76 \\
\hline
\end{tabular}


Table 7

Result of original (outlier excluded) and bootstrapped performance estimates.

\begin{tabular}{|c|c|c|c|c|}
\hline & \multicolumn{4}{|c|}{ Estimate } \\
\hline & Model 1 & Model 2 & Model 3 & Model 4 \\
\hline No of efficient DMUs & 14 & 21 & 16 & 39 \\
\hline$\%$ of total & 9.66 & 14.79 & 11.11 & 27.08 \\
\hline Original average efficiency score & 32.39 & 41.07 & 37.33 & 56.14 \\
\hline Average Bias-corrected efficiency score. & 24.41 & 33.31 & 30.51 & 50.94 \\
\hline Bias & 7.98 & 7.76 & 6.82 & 5.20 \\
\hline Standard deviation & 3.99 & 3.88 & 3.41 & 2.60 \\
\hline Average efficiency score of inefficient DMUs corrected & 16.26 & 21.64 & 21.75 & 32.54 \\
\hline Bootstrap median & 24.75 & 33.50 & 30.69 & 51.59 \\
\hline Lower bound & 12.93 & 23.11 & 21.03 & 43.68 \\
\hline Upper bound & 33.28 & 41.62 & 36.92 & 57.02 \\
\hline
\end{tabular}

that when a sector-average company incorporates OSN activity, the performance of its inputs improves by this ratio. Model 4 shows that, for businesses of this type, average inefficiencies are reduced by over 15\% (average efficiency increase of Model 4 with respect to Model 2 and Model 3), where the combination of activities on both platforms is employed, as against the use of only one of the platforms.

Due to the deterministic nature of the method DEA, the next step is the analysis of efficiency estimates in the presence of sample variations through the bootstrapping-DEA approach [70] (see Section 3). Table 7 reports the summary results for the efficiency scores using 2000 bootstrap replications $(B=2000)$ (under CCR DEA orientation) obtained by Models 1, 2, 3 and 4 . According to Simar and Wilson [70], an adequate coverage of the confidence intervals should be provided. The bootstrapping DEA approach results are also shown, including the average of the biascorrected efficiency scores, bias, standard deviation, and 95\% confidence intervals (lower bound and upper bound) for the bias corrected efficiency scores in the corresponding model (Table 8).

Since the estimated bias is larger than the standard deviation in every case, the bias-corrected efficiency estimates are preferred to the original efficiency estimates, as explained [36]. Therefore, the average bias-corrected efficiency scores were used in the analysis described hereafter. Analyzing the bootstrap confidence intervals, we can deduce conclusions concerning efficiency changes over models. Confidence intervals from Models 1, 2 and 3 overlap (the upper bound of one of them is greater than the lower bound of the next model), whereas the confidence interval of Model 4 does not overlap with any other. Therefore, it is possible to confirm a significant efficiency improvement of Model 4, compared to the other models.

Note that all the firms deemed efficient in Model 1 are also efficient in the other models (although there is no way of distinguishing between the five DMUs not involved in Web 2.0). Similarly, all firms efficient in Models 2 and 3 are efficient too in Model 4: i.e., those companies that efficiently incorporate at least one of the technologies are also efficient where they incorporate both. The combination of activities in both platforms has resulted in the addition of 4 extra efficient DMUs: these are large companies with a low level of activity on both platforms.

The potential input savings of incorporating at least one platform is $8.90 \%$ and $6.10 \%$ (average bias-corrected efficiency increase of Model 2 and Model 3 with respect to Model 1 , respectively). This means that when a sector-average company incorporates OSN activity, the performance of its inputs improves by this ratio. Model 4 shows that, for businesses of this type, average inefficiencies are reduced by almost 20\% (average biascorrected increase of Model 4 with respect to Model 2 and Model 3 ), where the combination of activities on both platforms is employed, as against the use of only one of the platforms.

At the individual level, it is clear that DMUs with similar characteristics in their input and output do not have similar efficiencies. This may be due to differing degrees of development of the management of the technology, or differing ways of incorporating it into their business strategy. (Appendix A reports the efficiency scores (original DEA and bootstrapped DEA) of all DMUs from Models 1-4. Blank scores mean that the DMU is an outlier of the model).

Looking at the subsectors according to NCEA classification, we observe how the growth of the bias-corrected efficiency with the incorporation of the combined technologies 2.0 is reflected in all subsectors except satellite telecommunications subsector. This subsector is strongly influenced by a small number of highly specialised companies with a very limited market. This market is characterised by public-private partnerships or jointventures.

Table 8

Result of original without outlier and bootstrapped performance estimates.

\begin{tabular}{|c|c|c|c|c|c|c|c|c|c|c|c|c|c|c|c|c|c|c|c|c|}
\hline \multirow[t]{2}{*}{ Estimate } & \multicolumn{4}{|c|}{$\begin{array}{l}61 \\
\text { Telecommunications } \\
\text { services }\end{array}$} & \multicolumn{4}{|c|}{$\begin{array}{l}6120 \\
\text { Wireless } \\
\text { telecommunications }\end{array}$} & \multicolumn{4}{|c|}{$\begin{array}{l}6190 \\
\text { Other } \\
\text { telecommunications } \\
\text { activities }\end{array}$} & \multicolumn{4}{|c|}{$\begin{array}{l}6110 \\
\text { Cable } \\
\text { telecommunications }\end{array}$} & \multicolumn{4}{|c|}{$\begin{array}{l}6130 \\
\text { Satellite } \\
\text { telecommunications }\end{array}$} \\
\hline & M 1 & M 2 & M 3 & M 4 & M 1 & M 2 & M 3 & M 4 & M 1 & M 2 & M 3 & M 4 & M 1 & M 2 & M 3 & M 4 & M 1 & M 2 & M 3 & M 4 \\
\hline No of efficient DMUs & 1.00 & 2.00 & 5.00 & 12.00 & 6.00 & 11.00 & 3.00 & 8.00 & 3.00 & 3.00 & 1.00 & 6.00 & 3.00 & 4.00 & 7.00 & 12.00 & 1.00 & 1.00 & 0.00 & 1.00 \\
\hline$\%$ of total subsector & 2.12 & 4.26 & 10.64 & 25.53 & 13.33 & 24.44 & 6.67 & 17.78 & 13.04 & 13.04 & 4.35 & 26.09 & 10.34 & 13.79 & 24.14 & 41.38 & 20.00 & 20.00 & 0.00 & 20.00 \\
\hline Original eff. Score & 19.57 & 31.71 & 37.86 & 55.00 & 51.69 & 57.30 & 38.21 & 56.58 & 48.09 & 41.58 & 35.45 & 64.87 & 25.60 & 38.84 & 40.16 & 55.77 & 45.46 & 48.48 & 17.42 & 45.68 \\
\hline Bias-corrected eff. & 9.11 & 23.38 & 30.95 & 49.96 & 45.61 & 49.99 & 30.88 & 50.78 & 37.85 & 34.38 & 25.35 & 59.75 & 18.79 & 30.82 & 34.47 & 50.60 & 33.79 & 40.19 & 9.69 & 41.21 \\
\hline Bias & 10.46 & 8.33 & 6.91 & 5.04 & 6.08 & 7.30 & 7.33 & 5.80 & 10.24 & 7.20 & 10.10 & 5.13 & 6.80 & 8.03 & 5.69 & 5.17 & 11.68 & 8.29 & 7.73 & 4.47 \\
\hline St Dev & 5.23 & 4.16 & 3.45 & 2.52 & 3.04 & 3.65 & 3.67 & 2.90 & 5.12 & 3.60 & 5.05 & 2.56 & 3.40 & 4.01 & 2.85 & 2.59 & 5.84 & 4.15 & 3.87 & 2.24 \\
\hline Bootstrap Median & 10.16 & 23.42 & 31.30 & 50.07 & 46.04 & 50.96 & 31.79 & 51.24 & 37.33 & 34.59 & 25.83 & 59.99 & 19.30 & 30.97 & 35.34 & 51.13 & 34.82 & 40.76 & 10.37 & 41.24 \\
\hline Lower bound & 6.67 & 14.05 & 23.84 & 43.16 & 38.35 & 38.97 & 21.41 & 42.57 & 26.32 & 24.95 & 13.46 & 52.05 & 9.92 & 20.15 & 25.33 & 42.61 & 18.96 & 30.83 & 1.74 & 34.50 \\
\hline Upper bound & 20.35 & 32.30 & 36.56 & 55.54 & 52.20 & 57.67 & 37.58 & 57.14 & 48.82 & 42.12 & 36.30 & 65.44 & 26.25 & 39.46 & 40.61 & 56.28 & 46.00 & 49.16 & 17.21 & 46.15 \\
\hline
\end{tabular}


Analysing the bootstrap confidence intervals, we can draw some conclusions concerning changes in efficiency over models and subsectors. The confidence interval of Model 4 does not overlap with any other confidence interval of any model in subsectors 61 telecommunications services, 6190 other telecommunications activities and 6110 cable telecommunications; therefore, it is possible to confirm a significant efficiency improvement of Model 4, compared to the other models in these three sectors. On the other hand, 6120 wireless telecommunications subsector have a definite improvement in efficiency with the incorporation of the Twitter platform (Model 2) with the largest percentage of efficient companies (24.44\%) in all the subsectors in this model. This result gives a very positive indicator of how companies of this subsector are incorporating customer services through this platform.

There are subsectors with higher efficiency scores in Model 2 (Twitter) and others in the Model 3 (Facebook). This reflects how the strengths that characterise each platform are better suited to different subsectors.

The average company in 61 telecommunications services and 6190 other telecommunications activities subsectors has improved efficiency through the Facebook platform: this seems consistent with the notion that this platform promotes deeper reflection expressed in its own style of language, which may lead to easier communication between firms. In contrast, the average efficiency of 6120 wireless telecommunications firms show more improvement with the use of the Twitter platform. This is consistent with the fact that on this platform, spontaneity, short messages and quick responses predominate. These might be the features of the costumers/clients service demanded for this subsector

For a further analysis of the impact of the use of Web 2.0. technologies by different companies, the final stage of this model is carried out. The impacts and the drivers of a good performance of technology 2.0, in the context of this study, reflect the ability of the telecommunication companies to shift the frontier of financial and technological achievements. We explore the factors that promote impact and the drivers of a good performance.

Qualitative variables that could not be used in the OSN-DEA model, both social media management (has blog, has YouTube, has a website, has mobile web platform .mobi) and business management (time span of the business, business model, international trade activities, belonging to a sub-sector) have been incorporated as independent variables in each of the logistic regression models applied. Defined a binary variable $Z$, as the dependent variable in all models, so that $Z=1$ for efficient firms (Model 4 efficiency score $=100$ ) and $Z=0$ for inefficient firms (Model 4 efficiency score $\leq 100$ ). The efficiency data are those obtained in Model 4 (see Table 6), since it includes all selected variables. Goodness-of-fit test based on the deviation explained by the model has been performed. Results of logistic regression models registered as p-value of the deviation analysis are shown in Table 9.

A significant relationship between the dependent variable $(Z)$ and OSN management variables (has blog, has YouTube, and has mobile web platform .mobi) and business management variables (business model, international trade activities, belonging to a subsector) have been found. In all cases, the value of the parameter $\beta_{1}$ of Eq. (4) has a positive sign. Therefore, it can be interpreted as a direct relationship between the use and possession of Web 2.0 tools (blog, YouTube channel and mobile web platform mobi) and the efficiency of the company's telecommunications sector in Spain. A company using these resources efficiently is characterised by not depending on the time span of the business, while fulfilling international trade activities. Therefore, it is a company seeking to open a market as broad as possible.

Moreover, the tenure of a website does not indicate a significant relationship with efficiency. The percentage of companies with a website amounts to $92.62 \%$. It can be assumed that it has become a homogeneous resource, with no restrictions of use by competitors. The combination of the remaining Web 2.0 tools can be considered as a heterogeneous and valuable resource, since there is a direct relationship between their joint use and the improvement of efficiency.

Finally, as there is a direct relationship between efficiency and the firm business orientation, it seemed interesting to carry out a pooled analysis of the telecommunications companies according to whether the company has a business model aimed at the final consumer (Business to Consumer: B2C) or at other businesses (Business to Business: $\mathrm{B} 2 \mathrm{~B}$ ). The incorporation of different platforms depending on the business orientation, gives an initial approximation to determine whether similar guidelines according to the type of business are applied in the design and implementation of the firms "social media" strategy. This analysis was deemed not valid when applied to Model 4: the small number of DMUs in the $\mathrm{B} 2 \mathrm{C}$ category generates a problem of scale, on which the discriminatory capacity of the methodology is dependent. Mahgary and Lahdelma [49] propound that the number of units tested must be at least three times the total number of variables; a condition not fulfilled in this case. The results are shown in Table 10.

The results in Table 10 indicate that the use of OSNs results in a greater relative impact on $\mathrm{B} 2 \mathrm{C}$-market organisations both in average efficiency values and in the proportion of efficient firms. These results show that the use of this resource is functionally different when used in different markets. The average company in the $\mathrm{B} 2 \mathrm{~B}$ market has improved efficiency through the Facebook platform. In contrast, the average efficiency of B2C-market businesses shows more improvement with the use of the Twitter platform. This reflects how the strengths that characterise each platform are better suited to different market and different customer orientation.
Table 9

Logistic regression results: $p$-value of the deviation analysis.

\begin{tabular}{ll}
\hline Business management & \\
\hline Timespan & 0.8375 \\
Business model & $0.0015^{*}$ \\
International trade & $0.0001^{*}$ \\
Sub-sector & $0.0204^{*}$ \\
Social media management & \\
Has Youtube & $0.0046^{*}$ \\
Has Blog & $0.0025^{*}$ \\
Has Website & 0.5823 \\
Has mobile web platforms MoBIi & $0.0116^{*}$ \\
\hline
\end{tabular}

Significant variable (significance level: $p$-value $<0.05$ ).
Table 10

Model results analysed according to business models (outliers excluded).

\begin{tabular}{lcccccccc}
\hline & \multicolumn{2}{l}{ B2B } & \multicolumn{5}{l}{ B2C } \\
\cline { 2 - 3 } \cline { 7 - 8 } & Model 1 & Model 2 & Model 3 & & Model 1 & Model 2 & Model 3 \\
\hline No efficient DMUs & 10 & 23 & 22 & 6 & 12 & 2 \\
\% Of total & 9.26 & 21.70 & 20.37 & & 16.22 & 33.33 & 5.56 \\
Original eff. score & 29.26 & 37.30 & 34.12 & & 40.76 & 50.37 & 43.90 \\
Bias-corrected eff. & 20.37 & 29.13 & 27.22 & & 33.19 & 43.15 & 34.64 \\
St dev & 4.44 & 4.08 & 3.45 & & 3.78 & 3.61 & 4.63 \\
Lower bound & 8.79 & 19.74 & 20.28 & & 25.01 & 32.55 & 24.60 \\
Upper bound & 30.18 & 38.38 & 34.39 & & 41.35 & 50.77 & 43.73 \\
No DMUs & 108 & 106 & 108 & 37 & 36 & 36 \\
\hline
\end{tabular}




\section{Discussion}

In a changing environment like the current one, the key point is not how good a technology is, but how well it is used by members of an organisation [74]. When individual companies are compared, the companies that are efficient after using Twitter or Facebook appear clearly to be using those resources in a way that brings greater efficiency than the other companies. In line with Peteraf [60], production factors used by firms have intrinsically different levels of efficiency, since some resources are superior to others. Furthermore, the same resources bring improved levels of efficiency to some companies but not to others. In some cases they are a source of competitive advantage, in others they are not. The activity that the companies develop in the OSNs engenders a positive change in the efficiency of some of them, which shows that the utilisation of OSN resources varies between firms.

Greater efficiency in the activities of the company implies a coordination of simple resources that combine to create more complex skills [9]. Competency is a set of knowledge and skills which, exercised through the coordinated deployment of the assets of the organisation process, determines the activities that the company is able to perform efficiently $[20,34]$. These considerations about all the coordinated actions in OSNs have been corroborated empirically by the second stage of the proposed model.

Furthermore, the results of this study coincide with Moyano Fuentes et al. [55], considering that the design and organisation of working practices should be treating online social networks (OSNs) as another business asset, or as a dimension of human capital that deserves attention.

When organisations are able to use their tangible and intangible assets to the highest possible level of efficiency, both costs and sales revenue will be appropriate, so that benefits will be generated at a rate proportional to the capital employed [68]. With regard to OSNs as an intangible asset of the companies, this study shows that every business can improve its efficiency by enhancing their OSN management capabilities and incorporating these Web 2.0 technologies into its business strategy.

Online social networks have a clear and direct influence on the companies that use them, as they represent a source of first-hand information for organisations: through them the needs and concerns of individuals who interact with them can be obtained. They also help reduce marketing costs, as large-scale marketing campaigns can partially be replaced by word-of-mouth communication that originates and propagates in these networks [43]. Likewise, technical service costs can be reduced, as the individuals who make up these networks help each other to solve problems encountered in the use of a product or service [24,77]. They promote bonding and strengthen loyalty towards the product, brand or organisation around which a network develops [42]. Along with these influences of OSN on companies, this study provides new empirical results that show that the incorporation of Web 2.0 technologies brings efficiency improvements that can be an early indicator of the creation of competitive advantage in terms of management capacity of these technologies, as only the management capacity of information technology is likely to generate a sustainable competitive advantage [53].

For the past several years there is an academic and scientific research line that aims to establish the relationship and contributions between the Information and Communication Technologies (ICTs) and the creation of competitive advantages in business. Although Carr [12] states that it is not possible to have unique, inimitable and heterogeneous information technology resources, Ramirez-Correa and Alfaro-Perez [62] indicate that the ability to manage these resources is in itself a potential and distinguishing strategic resource. Mata et al. [53] set out that the study of sustainable competitive advantages in relation to information technology (IT) should be performed considering the four attributes of IT: capital requirements, ownership of technology, ability and technical knowledge and management skills of these technologies. IT can add value to a firm, but does not generate a sustainable competitive advantage byitself; however, it is a necessary (but not sufficient) condition to achieve it [53].

From this perspective, this paper shows that the combined use and the appropriate management of OSN are configured as a heterogeneous resource. Once this resource is incorporated into business strategy, it generates an improvement of the efficiency of business organisations.

This paper identifies different factors that describe the performance in the use and management of Web 2.0. technologies and OSNs. The results of the assessment suggest that the fulfilling of international trade activities and the firm business orientation are factors and drivers that lead the firms to increase their performance in using and managing these technologies. It has also been obtained that companies with different business orientation (B2B or B2C) could achieve different levels of efficiency depending on the type of OSN that they use.

In order to take advantage of these Web 2.0 technologies benefits, it is necessary to ensure that participation levels are high enough to ensure network survivability in the long term [42]. It should be stressed that the relational benefits derived from consumer participation in a social network are already widely accepted in the academic community $[2,41,56]$ and in business [33].

Spanish telecommunications sector firms have developed two basic business strategies which place the customer at the core of attention. On the one hand, in order to swiftly achieve a critical mass of customers, they often use promotional pricing strategies. On the other hand, they follow loyalty strategies for customer retention which generate switching costs that prevent excessive rotation to other companies.

The companies have the strategic challenge of identifying their own social media users as a new group of stakeholders with influence on the progress of the company, that are not necessarily customers, but can be speakers of the goodness and shortcomings of the company [35]. Some social media users engage in behaviours of collaboration or participation that are essential in the process of value creation for the company [76].

Without the ability to define and measure the consequences of social media strategies, it is difficult for firms to align their social media initiatives with organisational goals and, at the end, create business value [19]. This concern is especially relevant given the speedy growth in the number of organisations interacting with customers through social media interfaces and the diversity of such channels for attracting customers [10].

This work provides a major result indicating that it is not just the number of users or fans of Web 2.0 technology that bring improvement in organisational efficiency, but that efficiency is directly related to the degree of integration of these technologies within the business plan, and to their influence on business strategy.

\section{Limitations and implications for future research}

This paper presents a model that provides a more robust and accurate efficiency estimation than the original DEA methodology. Due to the sensitivity of DEA measurements to the presence of outliers, a super-efficiency approach to detect outliers was introduced. In order to improve the deterministic nature of DEA model, a bootstrapping approach has been applied. However, this study presents several limitations. 
Firstly, we found some difficulties with the selection of the sample. The telecommunications sector or the type of companies included in the sample of the telecommunications industry is not clearly defined. This led to a wide disparity in the amount of telecommunications business. There is a fuzzy line between telecommunications and computing industry. The telecommunications market dynamism causes short-term variations. Thus, the selected sample was large enough to be discriminant according to number of inputs-outputs selected and to achieve the objectives of the study. Furthermore the influence of environment variables and other external data have not been considered.

Secondly, the statistical analysis of the variables that characterise the Web 2.0 technologies and OSNs is another limitation we have found. The values of these variables do not have a normal distribution which has led us to select the logistic regression analysis as statistical methodology in the later stage of this work. Furthermore, the monitoring of these variables has been done in a precise moment in time, so no conclusions about their evolution over time can be drawn.

In view of further research, it is suggested to include additional variables with relation to the new Web 2.0 tools that are increasing their presence over the recent years (Google+, Hangout and others). Besides, it would be interesting to develop a longitudinal study concerning the evolution over time of the presence and activity of these companies in the Web 2.0 tools regarding firm's efficiency, so the monitoring period should be increased.

Finally, future research could compare the productivity performance and the presence and activity in OSNs among several industries, although it would be necessary to assume the limitations of DEA on the homogeneity of the sample.

\section{Conclusions}

This paper studies the efficiency of firms in the telecommunications sector in Spain - both those that use Web 2.0 technologies and those that do not - and their ability to absorb those technologies and incorporate them into their business strategy. The telecommunications sector in Spain is a dynamic sector where the incorporation of these Web 2.0 technologies, both strategically and from a purely business standpoint, are necessary in order to succeed in the current market.

This study's results show that there is significant penetration of OSNs as a technological resource among the companies analysed. Furthermore, it has found a direct relationship between improved efficiency and the organisations using Web 2.0 technology. The fact that companies with similar characteristics in their inputs and outputs have not achieved similar efficiency can be attributed to varying degrees of development of management competences with this technology, or differing ways of incorporating it into their business strategy.

One of the main conclusions of this study is that the mere use of Web 2.0 technologies, measured in terms of numbers of users or fans, does not by itself lead to an improvement in the efficiency of an organisation. Each company may be able to improve their efficiency indicators by incorporating online social networks into their business strategy and refining skills involved in the use of Web 2.0 technologies.

The integrated DEA-model applied in this work, empirically suggests that only the companies capable of integrating these 2.0 technologies in their business plans and performing an activity and a coordinated management in several of these Web 2.0. technologies are the ones that obtained the largest efficiency gains.

According to the results of this work, it is strategically relevant for these firms to identify how social media is changing its traditional customer-firm and supplier-firm interactions and what new strategic goals are behind these changing relationships.

An understanding of proactive attention to customers and the new business dimension of social commerce are concepts that should be incorporated within the objectives of a company in order to exploit the full potential of Web 2.0 technologies. This study provides both researchers and business managers with a tool for assessing the strategic performance of an organisation with regard to its presence and activity in Web 2.0.

\section{Appendix A}

Efficiency scores (original DEA and bootstrapped DEA) of 149 DMUs from Models 1-4

\begin{tabular}{|c|c|c|c|c|c|c|c|c|}
\hline \multirow[t]{2}{*}{ DMU } & \multicolumn{2}{|l|}{ Model 1} & \multicolumn{2}{|l|}{ Model 2} & \multicolumn{2}{|l|}{ Model 3} & \multicolumn{2}{|l|}{ Model 4} \\
\hline & $\begin{array}{l}\text { Original } \\
\text { eff. Score }\end{array}$ & $\begin{array}{l}\text { Bias-corrected } \\
\text { eff. }\end{array}$ & $\begin{array}{l}\text { Original } \\
\text { eff. Score }\end{array}$ & $\begin{array}{l}\text { Bias-corrected } \\
\text { eff. }\end{array}$ & $\begin{array}{l}\text { Original } \\
\text { eff. Score }\end{array}$ & $\begin{array}{l}\text { Bias-corrected } \\
\text { eff. }\end{array}$ & $\begin{array}{l}\text { Original } \\
\text { eff. Score }\end{array}$ & $\begin{array}{l}\text { Bias-corrected } \\
\text { eff. }\end{array}$ \\
\hline A01 & 6.87 & 2.97 & 19.52 & 13.15 & 20.82 & 15.45 & 35.57 & 28.04 \\
\hline $\mathrm{A} 02$ & 30.28 & 21.85 & 35.03 & 30.27 & 17.28 & 11.37 & 51.04 & 45.84 \\
\hline $\mathrm{A} 03$ & 31.92 & 23.49 & 24.87 & 20.33 & 27.91 & 22.68 & 37.13 & 32.60 \\
\hline A04 & 14.65 & 2.96 & 43.87 & 21.00 & 18.75 & 13.75 & 27.39 & 24.77 \\
\hline A05 & 31.72 & 23.29 & 8.04 & 6.39 & 42.29 & 38.20 & 49.14 & 30.47 \\
\hline A06 & 3.95 & 2.75 & 5.48 & 2.95 & 6.40 & 4.93 & 19.44 & 16.38 \\
\hline $\mathrm{A} 07$ & 33.42 & 24.99 & 37.11 & 31.15 & 4.53 & 2.55 & 18.13 & 15.64 \\
\hline A08 & 17.94 & 7.39 & 30.12 & 21.73 & 34.81 & 24.57 & 45.98 & 41.10 \\
\hline $\mathrm{A} 09$ & 33.62 & 25.19 & 100 & 100 & 25.35 & 14.97 & 100 & 100 \\
\hline $\mathrm{A} 10$ & 18.05 & 6.72 & 27.55 & 17.71 & 100 & 100 & 100 & 100 \\
\hline $\mathrm{A} 11$ & 6.52 & 2.76 & 10.01 & 5.61 & 14.64 & 10.38 & 34.91 & 27.68 \\
\hline $\mathrm{A} 12$ & 32.02 & 23.59 & 18.88 & 14.70 & 8.38 & 4.67 & 21.58 & 15.23 \\
\hline A13 & 7.46 & 1.22 & 17.35 & 13.15 & 23.03 & 17.35 & 42.25 & 34.87 \\
\hline $\mathrm{A} 14$ & 33.22 & 24.79 & 30.15 & 22.25 & 15.63 & 11.42 & 48.37 & 32.49 \\
\hline $\mathrm{A} 15$ & 17.78 & 4.03 & 19.42 & 4.31 & 29.81 & 23.51 & 45.80 & 35.38 \\
\hline A16 & 9.77 & 5.13 & 11.39 & 4.60 & 18.22 & 6.02 & 18.38 & 13.56 \\
\hline A 17 & 2.07 & 0.86 & 6.33 & 5.11 & 10.98 & 5.87 & 19.76 & 15.89 \\
\hline A18 & 17.07 & 12.49 & 22.03 & 18.84 & 20.81 & 17.90 & 17.97 & 17.04 \\
\hline A19 & 30.52 & 22.09 & 8.98 & 6.82 & 16.95 & 12.85 & 25.31 & 23.50 \\
\hline A20 & 33.72 & 25.29 & 38.27 & 27.10 & 8.40 & 6.43 & 9.76 & 6.87 \\
\hline A21 & 31.52 & 23.09 & 14.46 & 12.02 & 30.39 & 19.62 & 39.60 & 33.99 \\
\hline A22 & 29.12 & 20.69 & 85.39 & 75.29 & 73.69 & 59.31 & 100 & 100 \\
\hline A23 & 19.12 & 10.69 & 57.62 & 34.44 & 84.90 & 74.35 & 85.39 & 78.61 \\
\hline A24 & 17.62 & 9.19 & 40.48 & 21.96 & 11.73 & 3.88 & 100 & 100 \\
\hline
\end{tabular}


Appendix A (Continued)

\begin{tabular}{|c|c|c|c|c|c|c|c|c|}
\hline \multirow[t]{2}{*}{ DMU } & \multicolumn{2}{|l|}{ Model 1} & \multicolumn{2}{|l|}{ Model 2} & \multicolumn{2}{|l|}{ Model 3} & \multicolumn{2}{|l|}{ Model 4} \\
\hline & $\begin{array}{l}\text { Original } \\
\text { eff. Score }\end{array}$ & $\begin{array}{l}\text { Bias-corrected } \\
\text { eff. }\end{array}$ & $\begin{array}{l}\text { Original } \\
\text { eff. Score }\end{array}$ & $\begin{array}{l}\text { Bias-corrected } \\
\text { eff. }\end{array}$ & $\begin{array}{l}\text { Original } \\
\text { eff. Score }\end{array}$ & $\begin{array}{l}\text { Bias-corrected } \\
\text { eff. }\end{array}$ & $\begin{array}{l}\text { Original } \\
\text { eff. Score }\end{array}$ & $\begin{array}{l}\text { Bias-corrected } \\
\text { eff. }\end{array}$ \\
\hline A25 & 33.62 & 25.19 & 71.24 & 55.03 & 53.51 & 44.59 & 41.22 & 35.10 \\
\hline A26 & 21.80 & 11.44 & 25.97 & 20.59 & 62.73 & 49.32 & 100 & 100 \\
\hline $\mathrm{A} 27$ & 3.37 & 0.59 & 11.27 & 9.27 & 17.28 & 17.68 & 31.06 & 27.57 \\
\hline A28 & 5.24 & 4.04 & 18.58 & 13.56 & 7.21 & 4.10 & 19.14 & 17.43 \\
\hline A29 & 100 & 100 & 100 & 100 & 100 & 100 & 100 & 100 \\
\hline A30 & 5.33 & 4.07 & 22.66 & 15.87 & 15.99 & 10.33 & 27.31 & 20.82 \\
\hline A31 & 3.74 & 2.41 & 14.05 & 10.80 & 20.39 & 5.50 & 30.39 & 25.83 \\
\hline A32 & 100 & 100 & 100 & 100 & 100 & 100 & 100 & 100 \\
\hline A33 & 25.62 & 17.19 & 53.29 & 25.83 & 52.22 & 26.54 & 11.32 & 7.35 \\
\hline \multicolumn{9}{|l|}{ A34 } \\
\hline A35 & 30.66 & 13.80 & 42.69 & 28.01 & 32.46 & 13.20 & 43.07 & 33.93 \\
\hline A36 & 74.26 & 51.35 & 100 & 100 & 31.27 & 18.45 & 100 & 100 \\
\hline A37 & 5.55 & 2.86 & 100 & 100 & 100 & 100 & 100 & 100 \\
\hline A38 & 40.61 & 22.57 & 83.02 & 68.86 & 64.74 & 42.94 & 53.71 & 38.35 \\
\hline A39 & 100 & 100 & 44.54 & 26.86 & 46.40 & 37.36 & 100 & 100 \\
\hline A40 & 100 & 100 & 100 & 100 & 100 & 100 & 100 & 100 \\
\hline A41 & 34.62 & 26.19 & 25.92 & 13.01 & 83.23 & 82.28 & 100 & 100 \\
\hline A42 & 13.72 & 5.29 & 20.55 & 16.22 & 39.49 & 35.47 & 61.34 & 50.36 \\
\hline A43 & 53.94 & 45.51 & 100 & 100 & 86.55 & 70.40 & 100 & 100 \\
\hline A44 & 26.83 & 7.77 & 59.35 & 30.32 & 74.30 & 60.04 & 100 & 100 \\
\hline A45 & 18.39 & 4.63 & 30.54 & 20.53 & 31.81 & 22.68 & 59.84 & 54.64 \\
\hline A46 & 34.37 & 25.94 & 31.94 & 22.35 & 35.80 & 31.25 & 45.94 & 40.74 \\
\hline A47 & 13.95 & 3.46 & 23.83 & 15.83 & 36.20 & 29.57 & 61.24 & 56.04 \\
\hline A48 & 11.37 & 6.62 & 22.53 & 10.31 & 13.94 & 6.96 & 37.91 & 22.39 \\
\hline A49 & 33.17 & 24.74 & 5.51 & 4.07 & 7.11 & 9.09 & 39.90 & 31.24 \\
\hline A50 & 32.95 & 24.52 & 25.90 & 16.20 & 18.09 & 7.91 & 47.09 & 33.06 \\
\hline A51 & 9.62 & 5.17 & 19.56 & 13.97 & 24.03 & 15.91 & 34.18 & 26.78 \\
\hline A52 & 42.23 & 13.78 & 59.00 & 36.30 & 18.71 & 14.45 & 19.54 & 18.09 \\
\hline A53 & 100 & 100 & 100 & 100 & 89.78 & 81.12 & 100 & 100 \\
\hline A54 & 8.88 & 5.89 & 14.16 & 11.66 & 100 & 100 & 100 & 100 \\
\hline A55 & & & & & & & & \\
\hline A56 & 20.03 & 13.71 & 20.03 & 9.13 & 27.04 & 14.87 & 30.19 & 17.09 \\
\hline A57 & 51.52 & 43.09 & 16.43 & 14.02 & 20.03 & 12.05 & 21.67 & 11.07 \\
\hline A58 & 28.24 & 9.40 & 31.08 & 25.02 & 29.38 & 26.69 & 24.38 & 22.98 \\
\hline A59 & 8.04 & 5.63 & 82.23 & 72.29 & 23.78 & 17.48 & 83.20 & 72.97 \\
\hline A60 & 15.10 & 5.63 & 79.42 & 62.62 & 80.00 & 68.43 & 97.11 & 94.40 \\
\hline A61 & & & & & & & & \\
\hline A62 & 31.04 & 17.18 & 42.55 & 32.59 & 8.93 & 6.05 & 44.48 & 37.92 \\
\hline A63 & 32.77 & 24.34 & 100 & 100 & 32.80 & 22.85 & 100 & 100 \\
\hline A64 & 32.73 & 24.30 & 100 & 100 & 100 & 100 & 100 & 100 \\
\hline A65 & 6.13 & 3.40 & 11.32 & 7.02 & 100 & 100 & 100 & 100 \\
\hline A66 & 42.66 & 34.23 & 53.39 & 24.43 & 10.14 & 8.25 & 19.53 & 16.64 \\
\hline A67 & 32.07 & 23.64 & 7.68 & 3.90 & 50.28 & 17.30 & 66.34 & 61.14 \\
\hline A68 & 3.28 & 0.36 & 12.30 & 9.90 & 14.93 & 10.80 & 18.97 & 10.87 \\
\hline A69 & 17.79 & 10.72 & 18.88 & 11.66 & 8.59 & 5.61 & 19.76 & 17.69 \\
\hline A70 & 7.99 & 3.08 & 12.40 & 8.04 & 17.94 & 12.16 & 24.07 & 17.46 \\
\hline A71 & 37.77 & 29.34 & 18.47 & 0.61 & 11.83 & 7.60 & 18.64 & 13.79 \\
\hline A72 & 100 & 100 & 100 & 100 & 100 & 100 & 100 & 100 \\
\hline A74 & 34.84 & 26.41 & 41.68 & 21.79 & 68.17 & 57.17 & 100 & 100 \\
\hline A75 & 33.73 & 25.30 & 39.11 & 33.29 & 38.09 & 19.16 & 78.43 & 66.26 \\
\hline A76 & 35.95 & 27.52 & 4.24 & 2.21 & 34.33 & 27.52 & 49.42 & 32.49 \\
\hline A77 & 100 & 100 & 100 & 100 & 100 & 100 & 100 & 100 \\
\hline A78 & 30.87 & 22.44 & 48.97 & 17.41 & 30.43 & 21.79 & 15.45 & 10.80 \\
\hline A79 & 4.20 & 3.00 & 10.01 & 6.40 & 48.49 & 19.86 & 51.57 & 39.95 \\
\hline A80 & 33.85 & 22.96 & 13.89 & 9.15 & 6.52 & 2.30 & 21.74 & 19.05 \\
\hline A81 & 30.03 & 19.68 & 32.68 & 20.00 & 11.28 & 6.55 & 24.32 & 21.25 \\
\hline A82 & 33.60 & 25.17 & 79.85 & 67.53 & 30.05 & 16.88 & 36.71 & 27.08 \\
\hline A83 & 1.50 & 1.29 & 16.07 & 9.23 & 38.16 & 31.56 & 79.99 & 72.73 \\
\hline A84 & 53.17 & 38.65 & 64.01 & 54.57 & 5.04 & 0.81 & 24.62 & 19.93 \\
\hline A85 & 11.30 & 2.87 & 19.39 & 16.29 & 39.59 & 32.05 & 65.23 & 58.84 \\
\hline A86 & 44.32 & 35.89 & 56.39 & 44.88 & 27.09 & 29.57 & 24.00 & 22.72 \\
\hline A87 & 34.96 & 26.53 & 24.19 & 16.43 & 27.77 & 20.18 & 70.98 & 57.57 \\
\hline A88 & 5.68 & 2.15 & 11.92 & 9.77 & 22.30 & 15.86 & 44.83 & 30.03 \\
\hline A89 & 54.79 & 18.80 & & & & & & \\
\hline A90 & 24.02 & 0.74 & 29.81 & 16.98 & 35.46 & 28.06 & 46.14 & 36.41 \\
\hline A91 & 41.52 & 33.09 & 84.54 & 72.19 & 47.49 & 40.27 & 100 & 100 \\
\hline A92 & 6.89 & 4.46 & 12.15 & 10.21 & 7.19 & 9.68 & 92.97 & 87.30 \\
\hline A93 & 44.96 & 36.53 & 19.00 & 15.25 & 19.18 & 16.08 & 19.41 & 17.87 \\
\hline A94 & 33.12 & 24.69 & 19.55 & 14.65 & 9.87 & 4.06 & 25.44 & 18.52 \\
\hline A95 & 32.63 & 10.78 & 13.63 & 4.69 & 18.80 & 15.25 & 29.73 & 18.43 \\
\hline A96 & 20.28 & 11.85 & 70.14 & 60.23 & 67.99 & 58.30 & 100 & 100 \\
\hline A97 & 23.72 & 15.29 & 6.54 & 5.49 & 12.40 & 6.54 & 46.17 & 33.84 \\
\hline A98 & & & & & & & & \\
\hline A99 & 20.92 & 12.49 & 27.76 & 17.95 & 3.61 & 2.39 & 18.07 & 16.93 \\
\hline A100 & 29.03 & 10.52 & 37.71 & 27.32 & 24.05 & 13.65 & 51.28 & 27.85 \\
\hline
\end{tabular}


Appendix A (Continued)

\begin{tabular}{|c|c|c|c|c|c|c|c|c|}
\hline \multirow[t]{2}{*}{ DMU } & \multicolumn{2}{|l|}{ Model 1} & \multicolumn{2}{|l|}{ Model 2} & \multicolumn{2}{|l|}{ Model 3} & \multicolumn{2}{|l|}{ Model 4} \\
\hline & $\begin{array}{l}\text { Original } \\
\text { eff. Score }\end{array}$ & $\begin{array}{l}\text { Bias-corrected } \\
\text { eff. }\end{array}$ & $\begin{array}{l}\text { Original } \\
\text { eff. Score }\end{array}$ & $\begin{array}{l}\text { Bias-corrected } \\
\text { eff. }\end{array}$ & $\begin{array}{l}\text { Original } \\
\text { eff. Score }\end{array}$ & $\begin{array}{l}\text { Bias-corrected } \\
\text { eff. }\end{array}$ & $\begin{array}{l}\text { Original } \\
\text { eff. Score }\end{array}$ & $\begin{array}{l}\text { Bias-corrected } \\
\text { eff. }\end{array}$ \\
\hline $\mathrm{A} 101$ & 100 & 100 & 100 & 100 & 100 & 100 & 100 & 100 \\
\hline $\mathrm{A} 102$ & 29.61 & 19.62 & & & 32.98 & 21.21 & 52.44 & 47.24 \\
\hline A103 & 61.34 & 33.54 & 75.89 & 57.74 & 67.88 & 60.46 & 46.50 & 40.56 \\
\hline $\mathrm{A} 104$ & 10.53 & 2.98 & 10.40 & 7.10 & 12.75 & 11.01 & 80.93 & 67.77 \\
\hline A105 & 31.64 & 23.21 & 7.21 & 4.94 & 6.21 & 3.82 & 36.13 & 24.72 \\
\hline A106 & 4.78 & 2.71 & 10.08 & 7.95 & 6.47 & 4.14 & 10.99 & 7.49 \\
\hline A107 & 19.15 & 37.66 & 25.43 & 22.04 & 17.19 & 20.10 & 19.83 & 17.07 \\
\hline A108 & 31.39 & 22.96 & 33.54 & 27.68 & 30.51 & 25.28 & 27.61 & 26.11 \\
\hline A109 & 17.87 & 9.44 & 28.83 & 24.44 & 27.11 & 23.57 & 35.23 & 31.56 \\
\hline A110 & 4.06 & 0.68 & 13.21 & 11.40 & 6.02 & 0.14 & 37.34 & 32.14 \\
\hline A111 & 5.65 & 1.10 & 16.15 & 12.88 & 7.57 & 4.64 & 19.98 & 15.97 \\
\hline A112 & 29.29 & 20.86 & 11.99 & 9.00 & 7.19 & 11.18 & 21.46 & 17.93 \\
\hline A 113 & 7.95 & 4.52 & 12.90 & 10.32 & 11.19 & 9.22 & 21.52 & 14.50 \\
\hline A114 & 100 & 100 & 100 & 100 & 100 & 100 & 100 & 100 \\
\hline A115 & 31.51 & 23.08 & 64.24 & 50.04 & 9.56 & 5.65 & 20.25 & 18.09 \\
\hline A116 & 30.40 & 21.97 & 100 & 100 & 25.43 & 21.36 & 100 & 100 \\
\hline A117 & 27.47 & 19.04 & 20.29 & 13.66 & 26.38 & 14.73 & 100 & 100 \\
\hline A118 & 100 & 100 & 100 & 100 & 100 & 100 & 100 & 100 \\
\hline A119 & 7.09 & 0.46 & 19.66 & 12.90 & 79.92 & 64.83 & 100 & 100 \\
\hline $\mathrm{A} 120$ & 100 & 100 & 66.94 & 53.79 & 100 & 100 & 100 & 100 \\
\hline A121 & 100 & 100 & 100 & 100 & 91.43 & 90.33 & 100 & 100 \\
\hline $\mathrm{A} 122$ & 3.63 & 0.50 & 15.58 & 8.94 & 17.30 & 11.71 & 67.61 & 47.21 \\
\hline $\mathrm{A} 123$ & 47.37 & 38.94 & 24.56 & 19.80 & 6.23 & 4.34 & 20.69 & 11.28 \\
\hline $\mathrm{A} 124$ & 12.75 & 3.32 & & & 45.61 & 39.14 & 74.94 & 69.74 \\
\hline A125 & 32.47 & 24.04 & 90.17 & 81.11 & 14.35 & 10.89 & 29.75 & 26.76 \\
\hline A 126 & 35.54 & 3.78 & 52.19 & 20.99 & 49.27 & 24.09 & 100 & 100 \\
\hline $\mathrm{A} 127$ & 53.49 & 45.06 & 100 & 100 & 95.64 & 89.88 & 100 & 100 \\
\hline A128 & 32.87 & 1.19 & 49.91 & 24.91 & 48.46 & 28.64 & 100 & 100 \\
\hline A129 & 13.45 & 10.39 & 100 & 100 & 34.06 & 12.06 & 100 & 100 \\
\hline A130 & 32.37 & 23.94 & 10.59 & 7.57 & 62.54 & 44.81 & 44.61 & 41.37 \\
\hline A131 & 32.29 & 23.86 & 18.20 & 13.43 & 8.38 & 4.45 & 21.32 & 15.89 \\
\hline A132 & 7.77 & 4.20 & 9.91 & 6.65 & 15.20 & 10.63 & 41.06 & 35.85 \\
\hline A 133 & 28.92 & 14.19 & 19.12 & 15.18 & 17.95 & 13.82 & 18.29 & 16.23 \\
\hline A 134 & 100 & 100 & 100 & 100 & 100 & 100 & 100 & 100 \\
\hline A135 & 33.92 & 24.89 & 24.17 & 16.73 & 14.77 & 10.71 & 21.93 & 18.37 \\
\hline A136 & 34.72 & 26.29 & 75.49 & 66.92 & 43.92 & 34.77 & 31.58 & 23.76 \\
\hline A137 & 21.92 & 14.30 & 32.66 & 25.25 & 31.06 & 22.36 & 76.12 & 69.47 \\
\hline A138 & 32.02 & 23.59 & 12.84 & 5.84 & 14.59 & 5.68 & 59.37 & 46.09 \\
\hline A139 & 2.28 & 1.74 & 4.98 & 3.76 & 12.46 & 6.08 & 26.99 & 17.54 \\
\hline $\mathrm{A} 140$ & 33.06 & 24.34 & 43.62 & 38.53 & 2.42 & 1.28 & 17.32 & 16.45 \\
\hline A 141 & 100 & 100 & 100 & 100 & 100 & 100 & 100 & 100 \\
\hline $\mathrm{A} 142$ & 33.22 & 24.79 & 59.86 & 32.85 & 18.13 & 12.35 & 55.53 & 34.13 \\
\hline A 143 & 32.82 & 24.39 & 22.07 & 4.31 & 29.43 & 6.13 & 68.54 & 51.33 \\
\hline $\mathrm{A} 144$ & 31.62 & 23.19 & 46.41 & 34.47 & 42.12 & 31.27 & 100 & 100 \\
\hline $\mathrm{A} 145$ & 3.17 & 2.13 & 11.20 & 8.64 & 9.60 & 5.64 & 20.63 & 17.16 \\
\hline A146 & 31.52 & 23.09 & 18.43 & 6.23 & 8.07 & 4.86 & 71.23 & 66.03 \\
\hline A 147 & 53.32 & 44.89 & 21.81 & 7.92 & 27.32 & 9.88 & 32.94 & 28.58 \\
\hline A148 & 49.08 & 21.95 & 60.83 & 39.12 & 4.38 & 1.38 & 82.05 & 68.36 \\
\hline A 149 & 19.42 & 7.23 & 21.08 & 10.14 & 60.56 & 38.96 & 74.01 & 61.70 \\
\hline
\end{tabular}

Blank scores mean that the DMU is an outlier of the model.

\section{Appendix B}

Pearson's correlation coefficients

\begin{tabular}{|c|c|c|c|c|c|c|c|c|c|c|c|c|}
\hline & EMPLOYEES & ASSETS & EQUITY & SALES & PROFITS & FANS & $\begin{array}{l}\text { COMMENT_ } \\
\text { received }\end{array}$ & POSTS & $\begin{array}{l}\text { Other } \\
\text { activities } \\
\text { Facebook }\end{array}$ & TWEETS & FOLLOWERS & FOLLOWING_Tweets \\
\hline EMPLOYEES & 1 & & & & & & & & & & & \\
\hline ASSETS & 0.2121 & 1 & & & & & & & & & & \\
\hline EQUITY & 0.1854 & 0.6648 & 1 & & & & & & & & & \\
\hline SALES & 0.4167 & 0.6125 & 0.5211 & 1 & & & & & & & & \\
\hline PROFITS & 0.6660 & 0.4160 & 0.6355 & 0.5639 & 1 & & & & & & & \\
\hline FANS & -0.0005 & -0.0128 & -0.0252 & 0.0520 & -0.0076 & 1 & & & & & & \\
\hline COMMENT_received & 0.0078 & -0.0124 & -0.0274 & 0.0781 & 0.0427 & 0.4416 & 1 & & & & & \\
\hline POSTS & 0.0044 & -0.0068 & -0.0180 & 0.0690 & 0.0067 & 0.6509 & 0.2548 & 1 & & & & \\
\hline $\begin{array}{l}\text { Other activities } \\
\text { Facebook }\end{array}$ & -0.0129 & -0.0107 & -0.0165 & -0.0055 & -0.0088 & $0.8357^{* *}$ & $0.7308^{* *}$ & 0.2321 & 1 & & & \\
\hline TWEETS & 0.1019 & 0.0286 & 0.0103 & 0.3901 & 0.2734 & 0.3862 & 0.5049 & 0.3473 & $0.8293^{* *}$ & 1 & & \\
\hline FOLLOWERS & 0.0271 & 0.0026 & -0.0148 & 0.1617 & 0.0953 & 0.8668 & 0.4241 & 0.7652 & $0.9284^{* *}$ & 0.5791 & 1 & \\
\hline FOLLOWING_Tweets & 0.1011 & 0.0692 & 0.0374 & 0.4600 & 0.4147 & 0.1069 & 0.3447 & 0.0737 & 0.0210 & 0.6609 & 0.4413 & 1 \\
\hline
\end{tabular}

\footnotetext{
** Rejected peer variables due to high correlation $(r>0.7)$.
} 


\section{References}

[1] A. Agresti, An Introduction to Categorical Data Analysis, John Wiley, New York, NY, 1996.

[2] P.H. Andersen, Relationship marketing and brand involvement of professionals through web-enhanced brand communities: the case of Coloplast, Ind. Mark. Manage. 34, 2005, pp. 39-51.

[3] P. Andersen, N.C. Petersen, A procedure for ranking efficient units in data envelopment analysis, Manage. Sci. 39 (10), 1993, pp. 1261-1264.

[4] N.K. Avkiran, Stability and integrity tests in data envelopment analysis, Socio Econ. Plan. Sci. 41 (3), 2007, pp. 224-234, doi: http://dx.doi.org/10.1016/ j.seps.2006.06.001.

[5] R.D. Banker, A. Charnes, W.W. Cooper, Some models for estimating technical and scale inefficiencies in data envelopment analysis, Manage. Sci. 30, 1984, pp. 1078 1092.

[6] R.D. Banker, R.M. Thrall, Estimating of returns to scale using data envelopment analysis, Eur. J. Oper. Res. 62 (1), 1992, pp. 74-84.

[7] C.P. Barros, C.A. Alves, Hypermarket retail efficiency in Portugal, Int. J. Retail Distrib. Manage. 31 (11), 2003, pp. 549-560.

[8] C.P. Barros, P.U.C. Dieke, Technical efficiency of African hotels, Int. J. Hosp. Manage. 27, 2008, pp. 438-447.

[9] J.A. Black, K.B. Boal, Strategic resources: traits, configurations and paths to sustainable competitive advantage, Strategic Manage. J. 15 (2), 1994, pp. 131 148.

[10] D.M. Boyd, N.B. Ellison, Social network sites: definition, history, and scholarship, J. Comput. Mediated Commun. 13 (1), 2008, pp. 210-230.

[11] P. Cantos, J.M. Pastor, L. Serrano, Efficiency measures and output specification: the case of European railways, J. Transp. Stat. 3, 2000, pp. 61-68.

[12] N.G. Carr, It doesn't matter, Harvard Bus. Rev. 81 (5), 2003, pp. 41-49.

[13] L.V. Casaló, C. Flavián, M. Guinalíu, Redes sociales virtuales desarrolladas por organizaciones empresariales: antecedentes de la intención de participaciôn del consumidor, Cuadernos de Economía y Dirección de la Empresa 15, 2012, pp. 4251, doi: 10.1016/j.cede.2011.06.003.

[14] M. Ceccobelli, S. Gitto, P. Mancuso, ICT capital and labour productivity growth: a non-parametric analysis of 14 OECD countries, Telecommun. Policy 36,2012, pp. 282-292, doi: 10.1016/j.telpol.2011.12.012.

[15] A. Charnes, W.W. Cooper, E. Rhodes, Measuring the efficiency of decision making units, Eur. J. Oper. Res. 2, 1978, pp. 429-444.

[16] A. Charnes, W. Cooper, S. Li, Using data envelopment analysis to evaluate efficiency in the economic performance of Chinese cities, Socio Econ. Plan. Sci. $23(6), 1989$, pp. 325-344.

[17] W. Cooper, J. Pastor, F. Borras, J. Aparicio, D. Pastor, BAM: a bounded adjusted measure of efficiency for use with bounded additive models, J. Prod. Anal. 35 2011, pp. 85-94, doi: $10.1007 / \mathrm{s} 11123-010-0190-2$.

[18] W.W.Cooper, L.M. Seiford, K. Tone, Data Envelopment Analysis, Kluwer Academic Publishers, Dordrecht, The Netherlands, 2000.

[19] M.J. Culnan, P.J. McHugh, J.I. Zubillaga, How large U.S. companies can use Twitter and other social media to gain business value, MIS Quart. Exec. 9 (4), 2010, pp. $243-260$.

[20] G.S. Day, The capabilities of market-driven organizations, J. Mark. 58 (4), 1994, pp. 37-52.

[21] R.M. Debnath, R. Ravi Shankar, Benchmarking telecommunication service in India: an application of data envelopment analysis, Benchmarking Int. J. 15 (5), 2008, pp. 584-598, doi: 10.1108/14635770810903169.

[22] L. Diaz-Balteiro, A.C. Herruzo, M. Martinez, J. González-Pachón, An analysis of productive efficiency and innovation activity using DEA: an application to Spain's wood-based industry, Forest Policy Econ. 8, 2006, pp. 762-773, doi: http:// dx.doi.org/10.1016/j.forpol.2005.06.004.

[23] DICODI, 50a Edición Base de Datos de Empresas Búsqueda de Clientes y Proveedores, Equifax, Madrid, 2011.

[24] U.M. Dholakia, S. Vianello, 35th EMAC Conference, 23-26 May 2006, Atenas, A study of sharing in consumer communities 2006.

[25] R. Durand, V. Vargas, Ownership, organization and private firms' efficient use of resources, Strategic Manage. J. 24, 2003, pp. 667-675.

[26] R.G. Dyson, R. Allen, A.S. Camanho, V.V. Podinovski, C.S. Sarrico, E.A. Shale, Pitfalls and protocols in DEA, Eur. J. For. Res. 132, 2001, pp. 245-259.

[27] B. Efron, Bootstrap methods: another look at the jacklnife, Ann. Stat. 7(1), 1979 , pp. $1-26$.

[28] A. Emrouznejad, E. Cabanda, R. Gholami, An alternative measure of the ICTOpportunity Index, Inf. Manage. 47, 2010, pp. 246-254, doi: 10.1016 / j.im.2010.04.002.

[29] A. Emrouznejad, E. Thanassoulis, Perfomance Improvement Management Software, (PIM-DEAsoft), 2006 Available from www.DEAsoftware.co.uk.

[30] L. Fang, A generalized DEA model for centralized resource allocation, Eur. J. Oper. Res. 228, 2013, pp. 405-412, doi: http://dx.doi.org/10.1016/j.ejor.2013.01.049.

[31] R. Farzipoor Saen, A. Memariani, F. Hosseinzadeh Lotfi, Determining relative efficiency of slightly non-homogeneous decision making units by data envelopment analysis: a case study in IROST, Appl. Math. Comput. 162 (2), 2005, pp. 503521.

[32] J. Fernández-Menéndez, J.I. López-Sánchez, A. Rodríguez-Duarte, F.D. Sandulli, Technical efficiency and use of information and communication technology in Spanish firms, Telecommun. Policy 33, 2009, pp. 348-359, doi: 10.1016/j.telpol.2009.03.003.

[33] Forum One Communications, Marketing \& Online Communities: Current Practice Research, Forum One Communications, 2007 July 2007.
[34] N.J. Foss, Introduction: the emerging competence perspective, in: N.J. Foss, C Knudsen (Eds.), Towards a Competence Theory of the Firm, Routledge, London, 1996, pp. 1-12.

[35] M. Foster, B.West, A. Francescucci, Exploring social media user segmentation and online brand profiles, J. Brand Manage. 19 (1), 2011, pp. 4-17, Suppl. Special Issue: Digital and Virtual World Research on Brands.

[36] H.O. Fried, C.A.K. Lovell, S.S. Schmidt, The Measurement of Productive Efficiency and Productivity Growth, Oxford University Press, Newy York, NY, US, 2008.

[37] D.A. Haas, F.H. Murphy, Compensating for non-homogeneity in decision-making units in data envelopment analysis, Eur. J. Oper. Res. 144, 2003, pp. 530-544.

[38] E. Hisali, B. Yawe, Total factor productivity growth in Uganda's telecommunications industry, Telecommun. Policy 35, 2011, pp. 12-19, doi: 10.1016/j.telpol.2010.10.004

[39] I. Horta, A.S. Camanho, J.M. Costa, Performance assessment of construction companies: a study of factors promoting financial soundness and innovation in the industry, Int. J. Prod. Econ. 137 (1), 2012, pp. 84-93, doi: http://dx.doi.org 10.1016/j.ijpe.2012.01.015.

[40] IZO, To Tweet or Not To Tweet: Estudio sobre la Presencia de las Marcas Españolas en Twitter para Atención al Cliente, IZO Innovation Labs y Observatorio Social Media, 2011 http://izo.es/wp-content/uploads/2011/01/IZO-Twitter-Engage-012011.pdf.

[41] V. Jeng, G.C. Lai, M.J. McNamara, Efficiency and demutualization: evidence from the U.S. Life Insurance Industry in the 1980s and 1990s, J. Risk Insur. 74, 2007, pp. $683-711$.

[42] J. Koh, D. Kim, Knowledge sharing in virtual communities: an e-business perspective, Expert Syst. Appl. 26, 2004, pp. 155-166.

[43] R.V. Kozinets, The field behind the screen: using netnography for marketing research in online communities, J. Mark. Res. 39, 2002, pp. 61-72.

[44] S. Lee, K. Lee, I.W. Kang, Efficiency analysis of controls in EDI applications, Inf. Manage. 42, 2005, pp. 425-439.

[45] A. Lenhart, M. Madden, Social Networking Websites and Teens: An Overview, Pew Internet \& American Life Project, Washington, DC, 2007, Disponible en: http:/ www.pewinternet.org/pdfs/PIP SNS Data Memo Jan 2007.pdf.

[46] D. Li, T. Nanseki, S. Takeuchi, Measurement of agricultural production efficiency and the determinants in China based on aEA approach: a case study of 99 farms from Hebei Province, J. Fac. Agr. Kyushu U. 57 (1), 2012, pp. 235-244.

[47] C. Lorenzo Romero, M.C. Alarcón De Amo, M.A. Gómez Borja, Adopción de redes sociales virtuales: ampliación del modelo de aceptación tecnológica integrando confianza y riesgo percibido, Cuadernos de Economía y Dirección de la Empresa 14, 2011, pp. 194-205, doi: 10.1016/j.cede.2010.12.003

[48] I. Mahdavi, H. Fazlollahtabar, E. Mozaffari, M. Heidari, N. Mahdavi-Amiri, Data envelopment analysis based comparison of two hybrid multi-criteria decisionmaking approaches for mobile phone selection: a case study in Iranian telecommunication environment, Int. J. Inf. Decis. Sci. 1 (2), 2008, pp. 194-220, doi: 10.1504/IJIDS.2008.022295.

[49] S. Mahgary, R. Lahdelma, Data envelopment analysis: visualizing the results, Eur. J. Oper. Res. 83 (3), 1995, pp. 700-710, doi: http://dx.doi.org/10.1016/03772217(94)00303-T.

[50] S.K. Majumdar, On the utilization of resources: perspectives from the U.S. tele communications industry, Strategic Manage. J. 19 (9), 1998, pp. 809-831.

[51] S.K. Majumdar, S. Venkataraman, Networks effects and the adoption of new technology: evidence from the U.S. telecommunications industry, Strategic Manage. J. 19 (11), 1998, pp. 1045-1062.

[52] R.O. Mason, D.A. Lind, W.G. Marchal, Statistics: An Introduction, Harcourt Brace Jovanovich, Inc., New York, NY, 1983 pp. 368-383.

[53] F.J. Mata, W.L. Fuerst, J.B. Barney, Information technology and sustained competitive advantage: a resource-based analysis, MIS Quart. 19 (4), 1995, pp. 487-505.

[54] Mckinsey \& Company, McKinsey Global Survey Results: How companies are benefiting fromWeb 2.0, Mckinsey \& Company, 2009 http://www.mckinseyquarterly.com/How_companies_are_benefiting_from_Web_20_ McKinsey_Global_Survey_Results_2432.

[55] J. Moyano Fuentes, S. Bruque Câmara, J. Eisenberg, La influencia de las redes sociales en la adaptación de los trabajadores al cambio tecnológico, Cuadernos de Economía y Dirección de la Empresa 10 (31), 2007, pp. 147-170.

[56] A. Muñiz, T.C. O'Guinn, Brand communities, J. Consum. Res. 27, 2001, pp. 412-432.

[57] N.R. Nataraja, A.L. Johnson, Guidelines for using variable selection techniques in data envelopment analysis, Eur. J. Oper. Res. 215 (3), 2011, pp. 662-669, doi: 10.1016 /j.ejor.2011.06.045

[58] T. O'Reilly, What is Web 2.0. Design Patterns and Bussiness Models for the Next Generation of Software, 2005 Disponible en: http://www.oreillynet.com/pub/a/ oreilly/tim/news/2005/09/30/what-is-web-20.html.

[59] J. Pastor, J.L. Ruiz, I. Sirvent, A statistical test for nested radial DEA models, Oper. Res. 50 (4), 2002, pp. 728-735.

[60] M. Peteraf, The cornerstones of competitive advantage: a resource-based view, Strategic Manage. J. 14, 1993, pp. 179-192.

[61] E.A. Ramalho, J.J.S. Ramalho, P.D. Henriques, Fractional regression models for second stage DEA efficiency analyses, J. Prod. Anal. 34, 2010, pp. 239-255.

[62] P. Ramírez-Correa, J. Alfaro-Perez, El nivel de la inversión en Tecnologías de Información no afecta al rendimiento empresarial: evidencia empitica de la industrias manufactureras chilenas, J. Technol. Manage. Innov. 6 (4), 2011, pp. 225-242.

[63] D. Reynolds, G.M. Thompson, Multiunit restaurant productivity assessment using three-phase data envelopment analysis, Int. J. Hosp. Manage. 26, 2007, pp. 20-32

[64] T.P. Ryan, Modem Regression Methods, John Wiley, New York, NY, 1997.

[65] R. Sellers, F. Mas, An empirical analysis of productivity growth in grocery retailing: evidence from Spain, Int. J. Serv. Ind. Manage. 18 (1), 2007, pp. 52-69. 
[66] C. Serrano-Cinca, Y. Fuertes-Callén, C. Mar-Molinero, Measuring DEA efficiency in Internet companies, Decis. Support Syst. 38 (4), 2005, pp. 557-573, doi: 10.1016 j.dss. 2003.08. 004.

[67] T.R. Sexton, R.H. Silkman, A.]. Hogan, Data envelopment analysis: critique and extensions, New Dir. Program Eval. 32, 1986, pp. 73-105.

[68] M. Sigala, The infomation and communication technologies productivity impact on the UK hotel sector, Int. J. Oper. Prod. Manage. 23 (10), 2003, pp. 1224-1245, doi: $10.1108 / 0144357031049664364$

[69] B. Silverman, Density Estimation for Statistics and Data Analysis. Monographs on Statistics and Applied Probability, Chapman \& Hall, London, 1986.

[70] L. Simar, P.W. Wilson, Sensitivity analysis of efficiency scores: how to bootstrap in nonparametric frontier models, Manage. Sci. 44, 1998, pp. 49-61.

[71] L. Simar, P.W. Wilson, Statistical inference in nonparametric frontier models: the state of the art, J. Prod. Anal. 13, 2000, pp. 49-78.

[72] L. Simar, P.W. Wilson, A general methodology for bootstrapping in nonparametric frontier models, J. Appl. Stat. 27, 2000, pp. 779-802.

[73] Territorio Creativo, Marketing en medios sociales: Cômo usan las empresas españolas los blogs y las redes sociales, Territorio Creativo, 2010 http://www.territoriocreativo.es/etc/2010/04/estudio-social-media-espana.html.

[74] G. Torlzzadeh, J. Lee, Measures of perceived end-user computing skílls, Inf. Manage. 40 (7), 2002, pp. 607-615.

[75] H. Tsai, C. Chen, G. Tzeng, The comparative productivity efficiency for global telecoms, Int. J. Prod. Econ. 103, 2006, pp. 509-526, doi: 10.1016/j.ijpe.2005. 11.001.

[76] E. von Hippel, Democratizing Innovation, MIT Press, Cambridge, MA, 2005, Free PDF available en http://web.mitedu/evhippel/www/books.htm.

[77] C. Wiertz, K. De Ruyter, Beyond the call of duty: why consumers contribute to firmhosted commercial online communities, Organiz. Stud. 28, 2007, pp. 347-376.

[78] O.E. Williamson, Strategizing, economizing, and economic organization, Strategic Manage. J. 12, 1991, pp. 75-94, doi: 10.1002/smj.4250121007.

[79] H. Yang, C. Chang, Using DEA window analysis to measure efficiencies of Taiwan's integrated telecommunication firms, Telecommun. Policy $33(1-2), 2009$, pp. $98-$ 108, doi: 10.1016/j.telpol.2008.11.001.

[80] W. Yu, R. Ramanathan, An assessment of operational efficiency of retail firms in China, J. Retailing Consum. Serv. 16, 2009, pp. 109-122, doi: 10.1016/j.jretconset.2008.11.009
[81] A.B. Wilson, B.J. Kerr, N.D. Bastian, L.V. Fulton, Financial performance monitoring of the technical efficiency of critical access hospitals: a data envelopment analysis and logistic regression modeling approach, J. Healthc. Manage. 57 (3), 2012, pp. $200-213$. 